\title{
Quality of care for knee osteoarthritis in primary care: a patient's perspective
}

Running title

Quality of care for knee osteoarthritis

\section{Authors}

David Spitaels ${ }^{1}$ MD; Patrik Vankrunkelsven ${ }^{1}$ MD, PhD; Lies Grypdonck ${ }^{2}$ MD; Frank-Robberecht Dusar $^{1}$ MD; Bert Aertgeerts MD, PhD ${ }^{1}$; Frank P. Luyten ${ }^{3}$ MD, PhD; Rosella P.M.G. Hermens ${ }^{1,4} \mathrm{PhD}$

\author{
Affiliations \\ ${ }^{1}$ Academic Centre for General Practice, KU Leuven, Leuven, Belgium \\ ${ }^{2}$ Former Academic Centre for General Practice, KU Leuven, Leuven, Belgium \\ ${ }^{3}$ Division of Rheumatology, University Hospitals Leuven, Leuven, Belgium \\ ${ }^{4}$ Radboud Institute for Health Sciences (RIHS), IQ Healthcare, Radboud University Medical Center
}

Correspondence

D. Spitaels, MD

Academic Centre for General Practice, KU Leuven

Kapucijnenvoer 33, J building, 3000 Leuven, Belgium

E-mail: david.spitaels@kuleuven.be

Conflict of interest and financial support

None to declare.

Word count

Manuscript: $\quad 3786 / 3800$ 


\section{ABSTRACT}

\section{Objective}

To describe the quality of osteoarthritis care in general practice from a patient's perspective and to identify novel associations between process quality indicators and patient-reported outcome and experience measures.

\section{Methods}

For this study, 235 persons with knee osteoarthritis completed a survey based on both process and outcome indicators. Process indicators were extracted from international guidelines and included the domains: diagnosis, self-management, treatment and follow-up. The Western Ontario McMaster Universities Osteoarthritis Index and RAND 36-Item Health Survey were used to assess patient-reported outcomes. Patients' reported experience with care was evaluated with the EUROPEP instrument. A series of multilevel regression analyses were then performed to analyze determinants at patient level (i.e. age, gender, BMI and education) and associations between process and outcome indicators.

\section{Results}

Overall, low adherence to the process indicators was observed (38\%), particularly on informing patients on the importance of weight loss $(24 \%, 95 \%$ CI: 19-31) or referring them for physical therapy $(41 \%, 95 \%$ CI: 33-49). Patients described their quality of life as moderate with an overall score of $63 \%$ and $35 \%$ on the RAND and WOMAC surveys, respectively. Regarding the determinants, patients with a higher educational level were better informed $(\mathrm{OR}=3.4$, $\mathrm{p}=0.0003$ ). Associations between process and outcome indicators were scarce, with the exception of patient satisfaction with care and use of NSAIDs ( $\mathrm{OR}=2.9, \mathrm{p}=0.0014)$.

\section{Conclusion}

Patients with knee osteoarthritis receive suboptimal conservative management. They report a moderate quality of life. This study confirms the evidence that NSAIDs are the backbone of osteoarthritis pain management, but now from a patient's perspective. 
- Adherence to quality indicators for the non-surgical management of knee osteoarthritis is particularly low for informing patients and referral for physical therapy.

- Patients with knee osteoarthritis experience a moderate quality of life.

- This study confirms the evidence that NSAIDs are the backbone of OA pain management, but now from a patient's perspective. 


\section{INTRODUCTION}

Osteoarthritis (OA) is the most common joint disorder and associated with severe long-term pain and impaired function (1). OA mainly affects the joints of the knees, hips, hands, facets and feet, but knee OA accounts for $83 \%$ of the total OA burden (2). Increase in life expectancy and ageing populations are expected to make OA the fourth leading cause of disability worldwide by the year 2020 (3). The economic burden is substantial and similar to that of coronary heart disease $(4,5)$.

Given the rise in prevalence and economic burden, there has been increasing interest in measuring the quality of care delivered to patients with knee OA. Quality indicators (QIs) are measurable tools in assessing and monitoring the quality of care (6). The classification of QIs is most commonly related to structure, process, or outcome of health care (7). 'Structure' denotes the attributes of the settings in which care occurs, while 'process' denotes what is actually done in giving and receiving care, and while 'outcome' measures describe the effects of care on the health status of patients (e.g. mortality, quality of life) (8). To measure the quality of healthcare for patients with knee OA, a Belgian set of 21 process QIs, based on international evidence-based guidelines, was developed by a multidisciplinary expert panel (9). Even though $\mathrm{OA}$ is one of the most prevalent conditions in general practice, evidence-based and valid QIs for assessing quality of primary care for knee OA are scarce (10). However, numerous studies have shown that high performance on process QIs does not consequently lead to the desired patient health outcomes $(11,12)$.

Moreover, although insight into the relation between process and outcome measures in realworld settings is crucial to improve quality of care, it remains poorly understood (13). In recent years, valid and identifiable patient-reported outcome and experience tools have become available for patients with knee problems (e.g. Cincinnati, IKDC, KOOS/WOMAC, KOSADL, Lysholm, Oxford, and WOMET) (14). These tools are used to measure patient 
experience with provided care, quality of life (QoL) and occasionally cost effectiveness from the patient's perspective (15).

Therefore, the aims of this study were to investigate (i) the performance of knee OA care in general practice from a patient's perspective using process QIs; (ii) patient-reported outcome and experience measures; (iii) associations between patient characteristics and process QIs; and (iv) associations between process QIs and patient-reported outcome and experience measures.

\section{METHOD}

Design

An observational study with questionnaires was conducted among patients with knee OA in Flanders (Belgium) and described in accordance with the STROBE recommendations for observational studies and reporting guidelines for conduct of survey research $(16,17)$. The questionnaire was based on the Belgian set of QIs and validated tools to assess the patients' quality of life and experience with care (9).

\section{Study population}

For this study, we used a purposive sampling strategy and addressed 81 GPs to invite patients with a confirmed clinical or radiological diagnosis of knee OA. GPs working in two different settings were involved: GPs using a specific software provider for the electronic health record (EHR) and GPs affiliated to an outpatient radiological screening centre. In the first setting, 32 GPs all users of a software provider (Medidoc), were contacted by letter. GPs were asked to select eligible patients with knee OA by performing an audit in their EHR. For this audit, a script had been formulated by the researchers (LG, $\mathrm{RH}$, and PV) to generate a list of patients diagnosed with knee osteoarthritis in a 12-month period. A diagnosis of knee OA, operationalized by the 'International Classification of Primary Care (ICPC)' was necessary for inclusion. Only patients who had visited their physician during the last year were taken into 
account with a maximum of 12 patients per physician to minimize sampling bias and to avoid possible oversampling by participating GPs. Patients were excluded for participation if they had a history of knee replacement surgery or if they did not master the Dutch language.

For the second setting, we recruited participants with a confirmed radiological diagnosis of knee OA by collaborating with a large provincial outpatient radiological screening centre. Patients who were referred for an X-ray by participating GPs were invited if knee osteoarthritis was included in the differential diagnosis. Permission of the 49 GPs who had requested the Xray was obtained beforehand. The radiological centre invited eligible patients by letter and sent a reminder to non-responders after 1 month. We also chose to include a maximum of 12 patients per participating GP for this setting. Group practices with shared patient care were considered equivalent to one GP.

\section{Data collection}

Patients were invited to participate by letter signed by their GP. Informed consent forms, an anonymized questionnaire and a prepaid return envelope were enclosed. The return envelope was sent directly to the researchers. The questionnaire and return envelope were marked by a unique code, which made it possible to trace patients recruited by the same GP. The questionnaire was distributed by letter, but also provided a link to a digital version of the questionnaire. Patients could thus choose both forms.

The questionnaire consisted of 54 questions divided into four subheadings (Supplement A):

\section{Personal data and background information.}

In this section the following patient characteristics were collected: age, gender, educational level, height, weight, sport activities and the time since first symptoms. To classify the patients' educational level we used a simplified version of the International Standard Classification of Education Index (18). A level of basic education was 
awarded to patients with a maximum degree of secondary school. Higher education was defined patients with a college or other tertiary educational level.

2. Care provided by the physician.

In this section 11 questions were ask in relationship to the management by their physician. These questions were based on the Belgian set of quality performance indicators for knee OA management (9). In this section patients were also asked about their experience with the physician. These patient-reported experiences were evaluated with the EUROPEP questionnaire, in which high scores represent high satisfaction with received care from the GP. Participants were asked to score 23 items, divided into five different domains: "relation and communication", "medical care", "information and support", "continuity and co-operation" and "accessibility" (19).

3. Care provided by the physical therapist.

If the patients received physical therapy, they were asked to clarify this treatment with 5 questions based on the Belgian set of performance QIs (9).

\section{Quality of life with knee osteoarthritis.}

For this part of the survey, patient-reported outcomes for knee OA severity and quality of life were included based on the disease-specific Western Ontario McMaster Universities Osteoarthritis Index (WOMAC) and the generic RAND 36-Item Health Survey 1.0 (SF-36). The RAND assessed 8 aspects: patients' physical functioning, bodily pain, role limitations due to physical health problems, role limitations due to personal or emotional problems, emotional wellbeing, social functioning, energy/fatigue, pain and general health perceptions (20). Scoring the RAND involved 3 steps: scoring the questions, averaging items to form 8 scales and calculating the scores. All questions were scored on a scale of 0 to 100 so that the lowest and highest possible scores were set at 0 and 100, respectively. The WOMAC consisted of 24 
questions about the effect of knee OA on quality of life and provides an overall score or a score in three subscales, "stiffness", "pain" and "functioning" (21).

Five patients screened a draft version of the questionnaire to check feasibility. Based on their evaluation, pictures were added to explain the physiotherapeutic treatment options, and medical information was written in patient-friendly language.

\section{Analysis}

Sample size estimate

Assuming accordance with the process QIs of 50\%, with an alpha of 0.05 , an estimation precision of $0.075,171$ patients need to be included.(22, 23) However, taking data clustering among clinicians into account, this number needs to be multiplied by the design effect. With a maximum of 12 patients per GP and an intra-cluster correlation coefficient of 0.02 , this effect is $1.22\left[=1+(12-1)^{*} 0.02\right]$ (24). Hence, the minimum number of patients to be included is 209 $[=1.22 \times 171]$. In order to compensate for a presumed response rate of $50 \%$ and $10 \%$ of incomplete data, a minimum of 523 patients have to be invited to participate.

Baseline patient characteristics and quality process indicators to assess knee OA management Descriptive statistics with frequency distributions were explored for age, gender, BMI, education level and sport activities. QI adherence was checked by matching questions with a binary response (yes/no) with an appropriate QI (Supplement B). A total of 14 process QIs, related to 'diagnosis', 'lifestyle/self-management', 'medication' or 'surgical interventions' were measured. From the set of 21 QIs, 7 QIs were not used in the patient questionnaire because they required professional evaluation, could not be translated into questions for patients or were out of scope for this study. Scores were presented as mean values with $95 \%$ confidence intervals. This analysis was performed by fitting logistic regression models with estimations based on generalized estimating equations (GEE) to account for clustering by the 64 participating GPs (25). 
Patient-reported outcomes and experiences

For the WOMAC score, the Cronbach's alpha was calculated for the three subscores and if 0.7 or higher, a total score was considered applicable (Supplement C). For further analysis, inverted percentages to the WOMAC score were calculated, with high scores defining a more favorable health state. All questions from the RAND-36 questionnaire were scored with the recommended approach on a scale from 0 to 100, with 100 representing the highest level of functioning possible. Aggregate scores were compiled as a percentage of the total points possible, using the RAND scoring table. The scores from questions addressing each specific area of functional health status were then averaged together, for a final score within each of the 8 dimensions measured (e.g. pain, physical functioning, etc.). For the EUROPEP instrument, the mean score of the five qualitative domains was calculated in case of a Cronbach's alpha over 0.7 (Supplement C). All 23 items are aggregated into two dimensions: clinical behavior (items 1-16) and organization of care (items 17-23). For describing frequency distributions with the EUROPEP instrument, response were scored 1, 2, 3, 4, 5, on a 5-point scale, running from poor (scored as 1) to excellent (scored as 5). Higher scores were equivalent to more satisfaction with provided care (26).

\section{Associations between process indicators and patient characteristics}

In order to define patient demographics that determine the quality of care, we looked for possible associations between process QIs and patient characteristics. All analyses in this study were performed by fitting logistic regression models with estimations based on GEE to account for clustering by the 64 participating GPs (25). Univariate logistic regression was performed to investigate associations between process indicator adherence and patient characteristics. The following patient characteristics were used as predictor variables for this analysis: patient's age, gender, BMI and educational level. Subsequently, a multivariate regression, with backward selection procedure, was performed for all characteristics with p-value $<0.10$ in the univariate analysis. All analyses were based on complete cases. All tests were two-sided. A 5\% 
significance level was assumed for all tests. No corrections for multiplicity were applied, given the exploratory nature of the study.

Associations between process indicators and patient reported outcomes and experiences Possible correlations between QIs and patient-reported outcomes and experiences were also investigated. For the patient-reported outcomes the RAND total and WOMAC subscores for pain, stiffness and function were used as predictor variables. For the patient-reported experiences we used the EUROPEP subscores for clinical behavior and organization of care. The same procedure was followed as in the determinant analysis: a multivariate regression, with backward procedure, was performed for all characteristics with p-value $<0.10$ in the univariate analysis. The final model was also corrected for patient characteristics. All analyses were performed using SAS software (version 9.4 of the SAS System for Windows).

\section{RESULTS}

\section{Baseline patient characteristics}

In total, 79\% ( $\mathrm{n}=64 / 81)$ of the addressed GPs, respectively 26 (out of 32) GPs of the EHR user group and 38 (out of 49) GPs related to the radiological center, wanted to participate and invited patients to complete the questionnaire. In total, 43\% $(n=235 / 543)$ of the invited patients (142 out of 223 from the EHR user group and 93 out of 320 from the radiological centre) returned a questionnaire. An overview of patient characteristics is presented in Table 1.

\section{Process quality indicators to assess knee OA management}

The management that patients received from their professionals was evaluated with a set of quality process QIs (9). From the patient questionnaire, 14 QI related to the perceived management by physicians and physical therapists were calculated. Patients reported an overall adherence of $38 \%$ to receiving these QIs with a range between $23 \%$ and $97 \%$ (Table 2). High adherence was found for QI related to physical therapy and pain management: patients should 
receive muscle strengthening $(76 \%$; $95 \% \mathrm{CI}: 61.5-86.0)$ and functional $(84 \%$; 95\%CI: 69.492.0) exercises by the physical therapist and patients should avoid strong opioids prescribed by their physician (97\%, 95\%CI: 93.6-98.6). Physiotherapists referred $79 \%$ of the patients to regular sports activities after their treatment. Regarding surgery, 168 participants had never undergone arthroscopy (72\%; 95\%CI: 64.8-77.3)) of the affected knee.

\section{Patient-reported outcomes and experiences}

The quality of life (QoL) assessed with the WOMAC checklist showed that patients with knee osteoarthritis experienced a moderate QoL measured by three inverted subscales: pain, stiffness and function, with $67 \%, 54 \%$ and $66 \%$, respectively. Also, the QoL assessed with the RAND36 Item survey showed moderate QoL with a total score of $63 \%$ and considerable variance between the eight subscales scores from $51 \%$ to $74 \%$. Patient experience with GP care showed high scores for all 23 items. The EUROPEP instrument for patient's evaluation of GP care showed an overall score of 4.4 both for the aggregated domain 'clinical behavior' and for the domain 'organization of care'.

\section{Associations between process indicators and patient characteristics}

Univariate analysis showed multiple associations between process QIs and age, BMI and educational level as predictor variables. The final model with multivariate analysis is presented in Table 3. An increased probability for not receiving arthroscopic interventions was associated with patients' increasing age (OR 1.06; $\mathrm{p}<0.0001)$. Increasing age of the patient was associated with lower adherence to the QI for evaluation by the physical therapist (OR $0.97 ; \mathrm{p}=0.0086$ ). A higher BMI was associated with higher adherence to the QIs concerning education about the importance of weight reduction (OR 1.27; $\mathrm{p}<0.0001)$, measures to unload damaged joints (OR 1.08; $\mathrm{p}=0.0221)$, encouragement for weight reduction if overweight $(\mathrm{OR} 1.22 ; \mathrm{p}=0.0003)$ and the percentage of patients with whom knee replacement surgery had been discussed (OR 1.12, 
$\mathrm{p}=0.0007)$. In the final model with multivariate analysis none of the QIs was associated with more than one patient characteristic.

\section{Associations between process indicators and patient-reported outcomes and experiences}

The final model with multivariate analysis is presented in Table 4. Predictor variables considered for the multivariable models were EUROPEP-clinical behavior, EUROPEPorganization of care, RAND total score, WOMAC pain score, WOMAC stiffness and WOMAC function score. Increased adherence to the QI regarding the intermittent use of NSAID was associated with higher QoL, defined by a higher score on the inverted WOMAC stiffness score (OR 1.04, $\mathrm{p}<0.0001)$. Good adherence to this QI also showed higher satisfaction with the organization of care by the GP (OR 2.9; $\mathrm{p}=0.0014)(27-30)$. In relationship to process QIs, we used the canonical threshold for good adherence of $80 \%$ or more, based on Haynes' definition of good adherence (31). We did not find an association for adherence to QI related to referral to a physical therapist for exercise training or to prescription of paracetamol for pain and predictor variables. Patients who did not receive arthroscopy were more satisfied by the organization of care (OR 2.0, $\mathrm{p}=0.0025)$ and they had better QoL defined by the WOMAC pain score (OR1.02, $\mathrm{p}=0.0011)$. The percentage of patients with whom knee replacement surgery had been discussed was correlated with lower QoL in the WOMAC pain (OR 0.97, p<0.0001).

\section{DISCUSSION}

We examined the quality of knee OA care in general practice from a patient's perspective, the relation between patients' characteristics and quality of care, as well as associations between process quality indicators and patient-reported outcome measures. Generally, patients reported a low adherence to process QIs, with an overall percentage of $38 \%$ and considerable variability (23\% to 97\%). Specifically, the process QIs showed low rates on QIs for patient education and referral for physical therapy. In contrast, patients receiving physical therapy reported care in line with QIs and knee OA practice guidelines. There was a high rate of patients that received 
arthroscopy, but more than half of them had a correct indication for the arthroscopic intervention. Avoiding strong opioids in the treatment of knee OA was the best adhered QI. Patients with knee OA described their QoL as moderate, with an overall score of $63 \%$ on the RAND-36 survey and similar scores for pain, stiffness and function on the WOMAC subscores. The EUROPEP instrument indicates that patients were very satisfied with GP care. The higher the patients' level of education, the more positive they were about receiving information on the importance of exercise. Associations between process QIs and patient-reported outcome measures were scarce, with the exception of the QI related to the prescription of antiinflammatory medication and patients' positive experiences with the organization of GP care.

The reported adherence to process QIs varied considerably in our study. Practitioners tended to score low in the field of health promotion and lifestyle advice, especially when compared with other European Union (EU) countries. In a European survey sent to people with selfreported OA, QI adherence for being informed varied from 55\% to $67 \%$, while in our study adherence was lower with scores between $23 \%$ and $43 \%$ (30). A minority of patients was informed about the importance of exercise (43\%), weight reduction (24\%) or the use of devices (23\%). In our study at least $86 \%$ of the patients were overweighed, but only $40 \%$ of these patients, reported having been advised to lose weight. Nevertheless, a higher BMI was associated with higher adherence to the QIs concerning encouragement for weight reduction. To maximize adherence to QIs concerning long-term treatment options such as selfmanagement, education and weight loss, treatment guidelines should clearly state which healthcare professional or professionals (e.g. GPs, rheumatologists, orthopedic specialists, physiotherapists, dieticians, occupational therapists, etc.) should be involved to achieve these QIs (32). Furthermore, in our study the low scores in the field of health promotion are explained by a Belgian study that compared the performance of the Belgian health system to 15 other EU countries: most aspects of the quality of care in Belgium are situated within the EU-15 average, 
but indicators on health promotion and lifestyle shows poor results, such as the stagnation of obesity in adults, the still high prevalence of daily smokers, the low rate of physical activity, and insufficient health literacy in the population (33). 'An ounce of prevention is worth a pound of cure' is a common saying, that could reflect the maximal conservative management for patients with knee OA, but unfortunately not yet achieved in the current healthcare settings.

In our study, almost three-quarters of the patients had no or a basic educational level. Once ignored as distant influences on health and disease, social determinants have been increasingly acknowledged as fundamental causes of health afflictions (34). The level of educational attainment is increasingly being recognized as an important social determinant of health (35). There are several pathways to link education with better health: more educated individuals will most likely make better-informed decisions, have lower rates of unemployment, and have a greater perceived personal control that leads to better health-related behavior $(35,36)$. We found a strong association between informing patients on the importance of exercise and their educational level (OR 3.4, $\mathrm{p}=0.0003)$. In response to chronic diseases, such as osteoarthritis, a responsive, proactive approach is increasingly considered a vital investment. Involving patients in the management process, multi-faceted care and integrated care with active patient involvement are strategies that are already in place in non-surgical management guidelines for knee OA management $(27,29,37)$. Now is the time to implement these strategies in daily practice.

Our study also shows that patients associate the intermittent use of NSAIDs with higher satisfaction with the organization of GP care. Pharmacological pain management of OA in primary care is dominated both by paracetamol and NSAID, as they are both recommended in evidence-based guidelines (27-30). Most guidelines recommend using paracetamol as the 'first-line' treatment for patients with a new pain episode, because NSAIDs have a serious side effect profile. However, recent meta-analyses consider NSAIDs to be the first choice of pain 
management for patients with osteoarthritis $(38,39)$. Patient perspectives could play an important role in evaluating if paracetamol should remain 'first-line' pain relief.

An important strength of our study is that not only adherence to process QIs and its determinants were assessed for patients with knee OA, but also their QoL and care experiences and possible associations between both. This is the first study in general practice that provides insights into the quality of care from the patient's perspective and analyses associations between process QIs, patient determinants and patient-reported outcomes and experiences. This study also has some limitations. The associations between process QIs and patientreported outcomes do not necessarily prove causality. There may be confounding variables, related to patient characteristics or comorbidities, which could have strengthened or weakened this association if they had been adjusted for. Adherence to QIs was assessed by patients, which may have resulted in underreporting of certain indicators. For example, for the QIs considering information or weight loss advice, particularly low scores were found. It may well be that practitioners provided their patients with this information as indicated, but not so thoroughly or not often enough. Improvement strategies might be tailored to help practitioners in their information provision to the patients. From another point of view, patient-reported aspects could be less accurate as it is difficult for patients to evaluate QIs concerning medications, physical therapy, etc. To overcome this burden, pictures of these treatments and thorough explanations of possible medications were included in the questionnaire.

In conclusion, this study showed low adherence and considerable variability to the guidelinebased process QIs from the patient's perspective. Patients with knee OA reported moderate quality of life. Associations between process and outcome indicators were scare, but patients' satisfaction was higher when anti-inflammatory medication was used during flares of knee osteoarthritis. NSAIDs are known to be the backbone of osteoarthritis pain management. We here provide evidence from the patient's perspective. The data indicate there is vast room for 
improvement in care of knee $\mathrm{OA}$, and that investing in quality of care is appropriate to improve guideline adherence. In future, patient-tailored strategies to improve patients' knowledge and self-management could be helpful to improve guideline adherence. 


\section{REFERENCES}

1. Murray CJ, Vos T, Lozano R, Naghavi M, Flaxman AD, Michaud C, et al. Disability-adjusted life years (DALYs) for 291 diseases and injuries in 21 regions, 1990-2010: a systematic analysis for the Global Burden of Disease Study 2010. Lancet 2012;380(9859):2197-223.

2. Vos T, Flaxman AD, Naghavi M, Lozano R, Michaud C, Ezzati M, et al. Years lived with disability (YLDs) for 1160 sequelae of 289 diseases and injuries 1990-2010: a systematic analysis for the Global Burden of Disease Study 2010. Lancet 2012;380(9859):2163-96.

3. Woolf AD, Pfleger B. Burden of major musculoskeletal conditions. Bull World Health Organ 2003;81(9):646-56.

4. Le Pen C, Reygrobellet C, Gerentes I. Financial cost of osteoarthritis in France. The "COART" France study. Joint Bone Spine 2005;72(6):567-70.

5. Cross M, Smith E, Hoy D, Nolte S, Ackerman I, Fransen M, et al. The global burden of hip and knee osteoarthritis: estimates from the global burden of disease 2010 study. Ann Rheum Dis 2014;73(7):1323-30.

6. Donabedian A. The quality of care. How can it be assessed? Jama 1988;260(12):1743-8.

7. McGlynn EA, Asch SM. Developing a clinical performance measure. Am J Prev Med 1998;14(3 Suppl):14-21.

8. Mainz J. Defining and classifying clinical indicators for quality improvement. Int J Qual Health Care 2003;15(6):523-30.

9. Grypdonck L, Aertgeerts B, Luyten F, Wollersheim H, Bellemans J, Peers K, et al. Development of quality indicators for an integrated approach of knee osteoarthritis. J Rheumatol 2014;41(6):1155-62.

10. Petrosyan Y, Sahakyan Y, Barnsley JM, Kuluski K, Liu B, Wodchis WP. Quality indicators for care of osteoarthritis in primary care settings: a systematic literature review. Fam Pract 2018;35(2):151-9.

11. Werner RM, Bradlow ET. Relationship between Medicare's hospital compare performance measures and mortality rates. Jama 2006;296(22):2694-702.

12. Krousel-Wood MA. Practical considerations in the measurement of outcomes in healthcare. Ochsner J 1999;1(4):187-94.

13. Mant J. Process versus outcome indicators in the assessment of quality of health care. Int J Qual Health Care 2001;13(6):475-80.

14. Wang D, Jones MH, Khair MM, Miniaci A. Patient-reported outcome measures for the knee. J Knee Surg 2010;23(3):137-51.

15. Weldring T, Smith SM. Patient-Reported Outcomes (PROs) and Patient-Reported Outcome Measures (PROMs). Health Serv Insights 2013;6:61-8.

16. von Elm E, Altman DG, Egger M, Pocock SJ, Gotzsche PC, Vandenbroucke JP. The Strengthening the Reporting of Observational Studies in Epidemiology (STROBE) statement: guidelines for reporting observational studies. Lancet 2007;370(9596):1453-7.

17. Kelley K, Clark B, Brown V, Sitzia J. Good practice in the conduct and reporting of survey research. Int J Qual Health Care 2003;15(3):261-6.

18. International Standard Classification of Education ISCED 2011. Available at www.uis.unesco.org. Accessed on 16 June 2019.

19. Dimova R, Stoyanova R, Keskinova D. The EUROPEP questionnaire for patient's evaluation of general practice care: Bulgarian experience. Croat Med J 2017;58(1):63-74.

20. Ware JE, Jr., Sherbourne CD. The MOS 36-item short-form health survey (SF-36). I. Conceptual framework and item selection. Med Care 1992;30(6):473-83.

21. McConnell S, Kolopack P, Davis AM. The Western Ontario and McMaster Universities Osteoarthritis Index (WOMAC): a review of its utility and measurement properties. Arthritis Rheum 2001;45(5):453-61.

22. Lugtenberg M, Burgers JS, Besters CF, Han D, Westert GP. Perceived barriers to guideline adherence: a survey among general practitioners. BMC Fam Pract 2011;12:98. 
23. McGlynn EA, Asch SM, Adams J, Keesey J, Hicks J, DeCristofaro A, et al. The quality of health care delivered to adults in the United States. N Engl J Med 2003;348(26):2635-45.

24. Killip S, Mahfoud Z, Pearce K. What is an intracluster correlation coefficient? Crucial concepts for primary care researchers. Ann Fam Med 2004;2(3):204-8.

25. Liang K-Y, Zeger SL. Longitudinal data analysis using generalized linear models. Biometrika 1986;73:13-22.

26. Flottorp SA, Oxman AD, Krause J, Musila NR, Wensing M, Godycki-Cwirko M, et al. A checklist for identifying determinants of practice: a systematic review and synthesis of frameworks and taxonomies of factors that prevent or enable improvements in healthcare professional practice. Implement Sci 2013;8:35.

27. McAlindon TE, Bannuru RR, Sullivan MC, Arden NK, Berenbaum F, Bierma-Zeinstra SM, et al. OARSI guidelines for the non-surgical management of knee osteoarthritis. Osteoarthritis Cartilage 2014;22(3):363-88.

28. Hochberg MC, Altman RD, April KT, Benkhalti M, Guyatt G, McGowan J, et al. American College of Rheumatology 2012 recommendations for the use of nonpharmacologic and pharmacologic therapies in osteoarthritis of the hand, hip, and knee. Arthritis Care Res (Hoboken) 2012;64(4):465-74.

29. Fernandes L, Hagen KB, Bijlsma JW, Andreassen O, Christensen P, Conaghan PG, et al. EULAR recommendations for the non-pharmacological core management of hip and knee osteoarthritis. Ann Rheum Dis 2013;72(7):1125-35.

30. Kingsbury SR, Gross HJ, Isherwood G, Conaghan PG. Osteoarthritis in Europe: impact on health status, work productivity and use of pharmacotherapies in five European countries. Rheumatology (Oxford) 2014;53(5):937-47.

31. Haynes RB, Sackett DL, Gibson ES, Taylor DW, Hackett BC, Roberts RS, et al. Improvement of medication compliance in uncontrolled hypertension. Lancet 1976;1(7972):1265-8.

32. Spitaels D, Hermens R, Van Assche D, Verschueren S, Luyten F, Vankrunkelsven P. Are physiotherapists adhering to quality indicators for the management of knee osteoarthritis? An observational study. Musculoskelet Sci Pract 2017;27:112-23.

33. Vrijens F, Renard F, Camberlin C, Desomer A, Dubois C, Jonckheer P, Van den Heede K, Van de Voorde C, Walckiers D, Léonard C, Meeus P. Performance of the Belgian Health System - Report 2015 - Health Services Research (HSR) Brussels: Belgian Health Care Knowledge Centre (KCE). 2016. KCE Reports 259C. D/2016/10.273/03.

34. Cockerham WC, Hamby BW, Oates GR. The Social Determinants of Chronic Disease. Am J Prev Med 2017;52(1s1):S5-s12.

35. Shankar J, Ip E, Khalema E, Couture J, Tan S, Zulla RT, et al. Education as a social determinant of health: issues facing indigenous and visible minority students in postsecondary education in Western Canada. Int J Environ Res Public Health 2013;10(9):3908-29.

36. Leganger A, Kraft P. Control constructs: Do they mediate the relation between educational attainment and health behaviour? J Health Psychol 2003;8(3):361-72.

37. Brown GA. AAOS clinical practice guideline: treatment of osteoarthritis of the knee: evidence-based guideline, 2nd edition. J Am Acad Orthop Surg 2013;21(9):577-9.

38. Machado GC, Maher CG, Ferreira PH, Pinheiro MB, Lin CW, Day RO, et al. Efficacy and safety of paracetamol for spinal pain and osteoarthritis: systematic review and meta-analysis of randomised placebo controlled trials. Bmj 2015;350:h1225.

39. da Costa BR, Reichenbach S, Keller N, Nartey L, Wandel S, Juni P, et al. Effectiveness of nonsteroidal anti-inflammatory drugs for the treatment of pain in knee and hip osteoarthritis: a network meta-analysis. Lancet 2016;387(10033):2093-105. 
Table 1. Baseline patient characteristics

\begin{tabular}{|c|c|c|}
\hline Variable & Statistic & Value \\
\hline Patients total & $\mathrm{N}$ & 235 \\
\hline Age (years) & Mean \pm SD [range] & $68.3 \pm 11.5[61.0 ; 77.0]$ \\
\hline$<50$ & $\mathrm{n} / \mathrm{N}(\%)$ & $13 / 233(5.6 \%)$ \\
\hline $50-64$ & $\mathrm{n} / \mathrm{N}(\%)$ & $75 / 233(32.2 \%)$ \\
\hline $65-74$ & $\mathrm{n} / \mathrm{N}(\%)$ & $72 / 233(30.9 \%)$ \\
\hline $75+$ & $\mathrm{n} / \mathrm{N}(\%)$ & $73 / 233(31.1 \%)$ \\
\hline \multicolumn{3}{|l|}{ Gender } \\
\hline Female & $\mathrm{n} / \mathrm{N}(\%)$ & $139 / 233(59.7 \%)$ \\
\hline BMI & Mean \pm SD [range] & $27.3 \pm 4.6[18.0 ; 41.7]$ \\
\hline Overweight (BMI >25) & $\mathrm{n} / \mathrm{N}(\%)$ & $144 / 217(66,4 \%)$ \\
\hline Obese $(\mathrm{BMI}>30)$ & $\mathrm{n} / \mathrm{N}(\%)$ & $58 / 217(26.7 \%)$ \\
\hline \multicolumn{3}{|l|}{ Education level } \\
\hline Basic educational level $^{\alpha}$ & $\mathrm{n} / \mathrm{N}(\%)$ & $168 / 227(74.0 \%)$ \\
\hline Higher educational level $^{\beta}$ & $\mathrm{n} / \mathrm{N}(\%)$ & $59 / 227(26.0 \%)$ \\
\hline $\begin{array}{l}\text { Period between start of the knee } \\
\text { symptoms and study participation } \\
\text { (years) }\end{array}$ & Mean \pm SD [range] & $11.1 \pm 11.0[1 ; 53]$ \\
\hline Regular sport activity as an adult & $\mathrm{n} / \mathrm{N}(\%)$ & $102 / 231(44.2 \%)$ \\
\hline First medical discipline consulted & $\mathrm{n} / \mathrm{N}(\%)$ & $\begin{array}{l}\text { GP; } 172 / 205(83.9 \%) \\
\text { Orthopedic surgeon; } 27 / 205(13.2 \%) \\
\text { Rheumatologist; } 1 / 205(0.5 \%) \\
\text { Physical medicine; } 3 / 205(1.5 \%) \\
\text { Other discipline; } 2 / 205(1.0 \%)\end{array}$ \\
\hline
\end{tabular}


Table 2. Adherence to process quality indicators and patient reported outcomes and experiences for knee osteoarthritis management

\begin{tabular}{|c|c|c|}
\hline A. QUALITY INDICATORS & $\begin{array}{l}\text { Achieved } \\
\text { n/N }(\%)\end{array}$ & $95 \% \mathrm{CI}$ \\
\hline \multicolumn{3}{|l|}{ Diagnosis } \\
\hline $\begin{array}{l}\text { QI1. Patients with recurrent effusion of the knee, should be further assessed with } \\
\text { aspiration of the knee in order to differentiate from inflammation. }\end{array}$ & $64 / 161 \quad(39.8 \%)$ & $31.8-48.3$ \\
\hline \multicolumn{3}{|l|}{ Lifestyle and non-pharmacological management strategies } \\
\hline $\begin{array}{l}\text { QI2. Patients should be given information, access and education about the importance } \\
\text { of exercise. }\end{array}$ & $101 / 235(43.0 \%)$ & $35.7-50.6$ \\
\hline $\begin{array}{l}\text { QI3. Patients should be information, access and education the importance of weight } \\
\text { reduction. }\end{array}$ & $57 / 235 \quad(24.3 \%)$ & $18.9-30.6$ \\
\hline $\begin{array}{l}\text { QI4. Patients should be given information, access and education about the importance } \\
\text { of measures to unload the damaged joint. }\end{array}$ & $53 / 235(22.6 \%)$ & $16.8-29.5$ \\
\hline $\begin{array}{l}\text { QI5. Overweight patients should be encouraged to lose weight and maintain his/her } \\
\text { weight at a lower level. }\end{array}$ & $58 / 144 \quad(40.3 \%)$ & $32.7-48.4$ \\
\hline QI6. Symptomatic patients should be referred to a physical therapist. & $94 / 231 \quad(40.7 \%)$ & $33.3-48.5$ \\
\hline $\begin{array}{l}\text { QI7. Patients should receive at least muscle strengthening exercises by the physical } \\
\text { therapist. }\end{array}$ & $47 / 62 \quad(75.8 \%)$ & $61.5-86.0$ \\
\hline QI8. Patients should receive at least functional exercises by the physical therapist. & $46 / 55 \quad(83.6 \%)$ & $69.4-92.0$ \\
\hline $\begin{array}{l}\text { QI9. Patients should be referred to regular sports activities after their treatment by the } \\
\text { physical therapist. }\end{array}$ & $51 / 65 \quad(78.5 \%)$ & $65.0-87.7$ \\
\hline \multicolumn{3}{|l|}{ Medication } \\
\hline QI10. Patients that received acetaminophen as oral pain medication. & $77 / 144 \quad(53.5 \%)$ & $43.5-63.1$ \\
\hline $\begin{array}{l}\text { QI11. If NSAID were used, then they should have been used intermittently (and not } \\
\text { continuously). }\end{array}$ & $93 / 135(68.9 \%)$ & $57.3-78.5$ \\
\hline QI12. Patients should not receive strong opioids. & $228 / 235(97.0 \%)$ & $93.6-98.6$ \\
\hline \multicolumn{3}{|l|}{ Surgical interventions } \\
\hline QI13. Knee arthroscopy should not be performed for patients with knee OA $*$ & $168 / 235(71.5 \%)$ & $64.8-77.3$ \\
\hline $\begin{array}{l}\text { QI14. Patients who experienced inadequate pain relief and functional improvement } \\
\text { and who received information about joint replacement surgery. }\end{array}$ & $87 / 226(38.5 \%)$ & $31.2-46.4$ \\
\hline Overall adherence to quality indicators & $38.4 \%$ & $35.5-41.2$ \\
\hline B. PATIENT REPORTED OUTCOMES: WOMAC and RAND-36 & Mean score $(\%)$ & SD \\
\hline WOMAC: subscale pain & $6.7 / 20 \quad(33.3)$ & 4.5 \\
\hline WOMAC: subscale stiffness & $(46.3)$ & 2.1 \\
\hline WOMAC: subscale function & $23.4 / 68$ & 15.9 \\
\hline WOMAC: total score & $33.6 / 96 \quad(34.9)$ & 21.3 \\
\hline RAND: total score & $62.2^{\alpha}$ & 21.4 \\
\hline \multicolumn{3}{|l|}{ C. PATIENT REPORTED EXPERIENCES: EUROPEP } \\
\hline Overall score: clinical behavior (items 1-16) & 4.4 & 0.7 \\
\hline Overall score: organization of care (items 17-23) & 4.4 & 0.7 \\
\hline $\begin{array}{l}\text { CI: confidence interval; SD: standard deviation; } \alpha \text { :percentage } \\
\text { Percentages and confidence interval from logistic regression with GEE to account for } \\
* 63 \%(n=38) \text { of all patients who received an arthroscopy }(n=60) \text { had locking signs of } \\
\text { surgery }\end{array}$ & $\begin{array}{l}\text { ering of the pract } \\
\text { nee at least once }\end{array}$ & $\begin{array}{l}\text { ners } \\
\text { ore }\end{array}$ \\
\hline
\end{tabular}


Table 3. Multivariate logistic regression: association between quality indicators and patient characteristics (age, gender, BMI, educational level)

\begin{tabular}{|c|c|c|c|c|c|c|c|}
\hline \multirow[t]{2}{*}{ Variable } & \multicolumn{2}{|c|}{ Age } & \multicolumn{2}{|c|}{ BMI } & \multicolumn{2}{|c|}{ Education } & \multirow[b]{2}{*}{$\mathbf{N}$} \\
\hline & $\begin{array}{c}\text { OR } \\
(95 \% \mathrm{CI})\end{array}$ & p-value & $\begin{array}{c}\text { OR } \\
(95 \% \mathrm{CI})\end{array}$ & p-value & $\begin{array}{c}\text { OR } \\
(95 \% \mathrm{CI})\end{array}$ & p-value & \\
\hline \multicolumn{8}{|l|}{ Diagnosis } \\
\hline $\begin{array}{l}\text { QI1. Pts received a punction after } \\
\text { recurrent effusion. }\end{array}$ & $\begin{array}{c}0.96 \\
(0.94 ; 0.99)\end{array}$ & 0.0010 & & $\cdot$ & & . & 160 \\
\hline \multicolumn{8}{|c|}{ Lifestyle and self-management strategies } \\
\hline $\begin{array}{l}\text { QI2. Pts educated on the importance } \\
\text { of exercise. }\end{array}$ & & 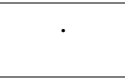 & & $\cdot$ & $\begin{array}{c}3.4 \\
(1.77 ; 6.62)\end{array}$ & 0.0003 & 227 \\
\hline $\begin{array}{l}\text { QI3. Pts educated on the importance } \\
\text { of weight reduction. }\end{array}$ & & . & $\begin{array}{c}1.27 \\
(1.18 ; 1.37)\end{array}$ & $<0.0001$ & & . & 217 \\
\hline $\begin{array}{l}\text { QI4. Pts educated to unload a } \\
\text { damaged joint. }\end{array}$ & & . & $\begin{array}{c}1.08 \\
(1.01 ; 1.15)\end{array}$ & 0.0221 & & . & 217 \\
\hline $\begin{array}{l}\text { QI5. Overweight pts encouraged to } \\
\text { lose weight. }\end{array}$ & & . & $\begin{array}{c}1.22 \\
(1.09 ; 1.36)\end{array}$ & 0.0003 & & . & 144 \\
\hline $\begin{array}{l}\text { QI7. Pts received at least muscle } \\
\text { strengthening exercises } \\
\text { by the physical therapist }\end{array}$ & $\begin{array}{c}0.93 \\
(0.89 ; 0.98)\end{array}$ & 0.0106 & & . & & . & 61 \\
\hline $\begin{array}{l}\text { QI9. Pts referred to sports activities } \\
\text { after physiotherapy. }\end{array}$ & $\begin{array}{c}0.97 \\
(0.94 ; 0.99) \\
\end{array}$ & 0.0086 & & . & & . & 229 \\
\hline \multicolumn{8}{|l|}{ Surgical interventions } \\
\hline $\begin{array}{l}\text { QI13. Pts that did not receive } \\
\text { arthroscopy. }\end{array}$ & $\begin{array}{c}1.06 \\
(1.03 ; 1.09)\end{array}$ & $<0.0001$ & & . & & . & 233 \\
\hline $\begin{array}{l}\text { QI14. Pts that were informed on joint } \\
\text { replacement surgery. }\end{array}$ & & . & $\begin{array}{c}1.12 \\
(1.05 ; 1.20)\end{array}$ & 0.0007 & & . & 209 \\
\hline
\end{tabular}


Table 4. Multivariate logistic regression: association between quality indicators and patient reported outcomes/ experiences with correction for patient characteristics

\begin{tabular}{|c|c|c|c|c|c|c|c|c|c|c|c|}
\hline \multirow[t]{2}{*}{ Variable } & \multicolumn{2}{|c|}{$\begin{array}{c}\text { Europep } \\
\text { organization }\end{array}$} & \multicolumn{2}{|c|}{ RAND total } & \multicolumn{2}{|c|}{ WOMAC pain } & \multicolumn{2}{|c|}{ WOMAC stiffness } & \multicolumn{2}{|c|}{$\begin{array}{l}\text { WOMAC } \\
\text { function }\end{array}$} & \multirow[b]{2}{*}{$\mathbf{N}$} \\
\hline & $\begin{array}{c}\text { OR } \\
(95 \% \mathrm{CI})\end{array}$ & $\begin{array}{c}\text { p- } \\
\text { value }\end{array}$ & $\begin{array}{c}\text { OR } \\
(95 \% \mathrm{CI})\end{array}$ & $\begin{array}{c}\text { p- } \\
\text { value }\end{array}$ & $\begin{array}{c}\text { OR } \\
(95 \% \mathrm{CI})\end{array}$ & $\begin{array}{c}\text { p- } \\
\text { value }\end{array}$ & $\begin{array}{c}\text { OR } \\
(95 \% \mathrm{CI})\end{array}$ & $\begin{array}{c}\text { p- } \\
\text { value }\end{array}$ & $\begin{array}{c}\text { OR } \\
(95 \% \mathrm{CI})\end{array}$ & $\begin{array}{c}\text { p- } \\
\text { value }\end{array}$ & \\
\hline \multicolumn{12}{|l|}{ Diagnosis } \\
\hline $\begin{array}{l}\text { QI1. Pts received a } \\
\text { punction after } \\
\text { recurrent effusion. }\end{array}$ & & & $\begin{array}{c}0.97 \\
(0.95 ; 0.98)\end{array}$ & $\begin{array}{c}<0.000 \\
1\end{array}$ & & . & & . & & . & 138 \\
\hline \multicolumn{12}{|c|}{ Lifestyle and self-management strategies } \\
\hline $\begin{array}{l}\text { QI2. Pts educated on } \\
\text { the importance of } \\
\text { exercise. }\end{array}$ & $\begin{array}{c}0.57 \\
(0.36 ; 0.93)\end{array}$ & 0.0233 & & . & & . & & . & & . & 196 \\
\hline $\begin{array}{l}\text { QI3. Pts educated on } \\
\text { the importance of } \\
\text { weight reduction. }\end{array}$ & & . & & . & & . & $\begin{array}{c}0.99 \\
(0.97 ; 1.00)\end{array}$ & 0.0305 & & . & 208 \\
\hline $\begin{array}{l}\text { QI4. Pts educated to } \\
\text { unload a damaged } \\
\text { joint. }\end{array}$ & & . & & $\cdot$ & & . & & . & $\begin{array}{c}0.97 \\
(0.95 ; 0.99)\end{array}$ & 0.0030 & 208 \\
\hline $\begin{array}{l}\text { QI5. Overweight pts } \\
\text { encouraged to lose } \\
\text { weight. }\end{array}$ & & . & $\begin{array}{c}0.98 \\
(0.97 ; 0.99)\end{array}$ & 0.0356 & & . & & . & & . & 128 \\
\hline $\begin{array}{l}\text { QI9. Pts referred to } \\
\text { sports activities after } \\
\text { physiotherapy. }\end{array}$ & $\begin{array}{c}0.56 \\
(0.35 ; 0.92)\end{array}$ & 0.0220 & & . & & . & & . & & . & 195 \\
\hline \multicolumn{12}{|l|}{ Medication } \\
\hline $\begin{array}{l}\text { QI11. Pts that } \\
\text { received NSAIDs } \\
\text { intermittently. }\end{array}$ & $\begin{array}{c}2.93 \\
(1.51 ; 5.67)\end{array}$ & 0.0014 & & . & & . & $\begin{array}{c}1.04 \\
(1.02 ; 1.05)\end{array}$ & $\begin{array}{c}<0.000 \\
1\end{array}$ & & . & 120 \\
\hline $\begin{array}{l}\text { QI12. Pts that did not } \\
\text { receive strong } \\
\text { opioids. }\end{array}$ & $\begin{array}{c}1.97 \\
(1.25 ; 3.10)\end{array}$ & 0.0035 & $\begin{array}{c}1.04 \\
(1.01 ; 1.07)\end{array}$ & 0.0112 & & . & & . & & .. & 179 \\
\hline \multicolumn{12}{|l|}{ Surgical interventions } \\
\hline $\begin{array}{l}\text { QI13. Pts that did not } \\
\text { receive arthroscopy. }\end{array}$ & $\begin{array}{c}1.95 \\
(1.27 ; 3.01)\end{array}$ & 0.0025 & & . & $\begin{array}{c}1.02 \\
(1.01 ; 1.04)\end{array}$ & 0.0011 & & . & & . & 193 \\
\hline $\begin{array}{l}\text { QI14. Pts that were } \\
\text { informed on joint } \\
\text { replacement surgery. }\end{array}$ & & & & . & $\begin{array}{c}0.97 \\
(0.95 ; 0.98)\end{array}$ & $\begin{array}{c}<0.000 \\
1\end{array}$ & & . & & . & 201 \\
\hline $\begin{array}{l}\mathrm{N}=\text { Number of included } \\
\text { Confidence interval } \\
\text { The dependent variable }\end{array}$ & ; Pts = pati & $\mathrm{s} ; \mathrm{OR}=$ & $\begin{array}{l}\text { Ids Ratio: Ol } \\
\text { hheld for any }\end{array}$ & $\begin{array}{l}(<) 1: \text { ir } \\
\text { and thu }\end{array}$ & eased (decre & $\begin{array}{l}\text { d) proba } \\
\text { he table }\end{array}$ & ity of good & rence & increasing & $\mathrm{el}$ CI = & \\
\hline
\end{tabular}

